\title{
DESIGN AND DEVELOPMENT OF AUTO DEPTH CONTROL OF REMOTELY OPERATED VEHICLE USING THRUSTER SYSTEM
}

\author{
F.A. Ali, M.S.M. Aras, F.A. Azis, M.F. Sulaima and I. Jaaffar \\ Faculty of Engineering Technology, \\ Faculty of Electrical Engineering, Universiti Teknikal Malaysia Melaka, \\ Hang Tuah Jaya, 76100 Durian Tunggal, Melaka, MALAYSIA. \\ Email: fara@utem.edu.my \\ Phone:+6062346409; Fax:+6062346526
}

\begin{abstract}
Remotely Operated Vehicles are underwater robots designed specifically for surveillance, monitoring and collecting data for underwater activities. In the underwater vehicle industries, the thruster is an important part in controlling the direction, depth and speed of the ROV. However, there are some ROVs that cannot be maintained at the specified depth for a long time because of disturbance. This paper proposes an auto depth control using a thruster system. A prototype of a thruster with an auto depth control is developed and attached to the previously fabricated UTeM ROV. This paper presents the operation of auto depth control as well as thrusters for submerging and emerging purposes and maintaining the specified depth. The thruster system utilizes a microcontroller as its brain, a piezoresistive strain gauge pressure sensor and a DC brushless motor to run the propeller. Performance analysis of the auto depth control system is conducted to identify the sensitivity of the pressure sensor, and the accuracy and stability of the system. The results show that the thruster system performs well in maintaining a specified depth as well as stabilizing itself when a disturbanceoccurs even with a simple proportional controller used to control the thruster, where the thruster is an important component of the ROV.
\end{abstract}

Keywords: Remotely operated vehicle; auto depth control; thruster; pressure sensor.

\section{INTRODUCTION}

Nowadays, underwater research is becoming popular among scientists and researchers. New vehicles that can submerge into deep oceans are invented day by day. Remotely Operated Vehicles (ROV) is a very common vehicle for underwater researchers, helping them investigate underwater species at the bottom of the ocean that are normally beyond the reach of humans. There is emphasis on the difficulty of conducting these operations at such extreme depths, where humans cannot directly interact with malfunctioning equipment [1]. ROVs are divided into several classes referring to their work ability. The first class is for pure observation, focuses on video observation and is usually small in size and lightweight. The second class is for observation with a payload option, where the vehicle must be capable of carrying additional sensors. The third and fourth classes are working class vehicles and seabed working vehicles, respectively [2]. Generally, ROVs have already been developed with a thruster which controls the direction, depth and speed. The thruster makes the ROV move up, down, forwards, in reverse, right and left. For maintaining the ROV underwater at a specified depth for a long time, some of 
the fabricated ROVs are already installed with an auto depth control system using a thruster or ballast tank. The significance of this study was to develop a simple controller that can guarantee the suppression or at least limitation of overshoot in the system response for depth control. The modelling of thrusters is reported in Aras et al. [3] and Ali et al. [4]. The system indirectly helps the researcher to record a video and take samples at certain depths and has been applied in the oil and gas industries to carry out inspecting or monitoring jobs on pipes or chains [5]. This paper presents the design and development of a prototype thruster with an auto depth control system. The prototype of the ROV was developed by the Underwater Technology Research Group (UTeRG) at the Universiti Teknikal Malaysia Melaka, as shown in Figure 1. The details of the design and specifications of this ROV can be found in Aras et al. [6], Azis et al. [7] and Aras et al. [8]. The prototype was invented as an enhancement of the previously fabricated UTeM ROV in terms of depth control. The important functions considered in developing the thruster are accuracy and stability [9]. Thus, the thruster moves autonomously underwater and maintains itself at the specified depth as well as stabilizing itself in the initial position when disturbances occur.

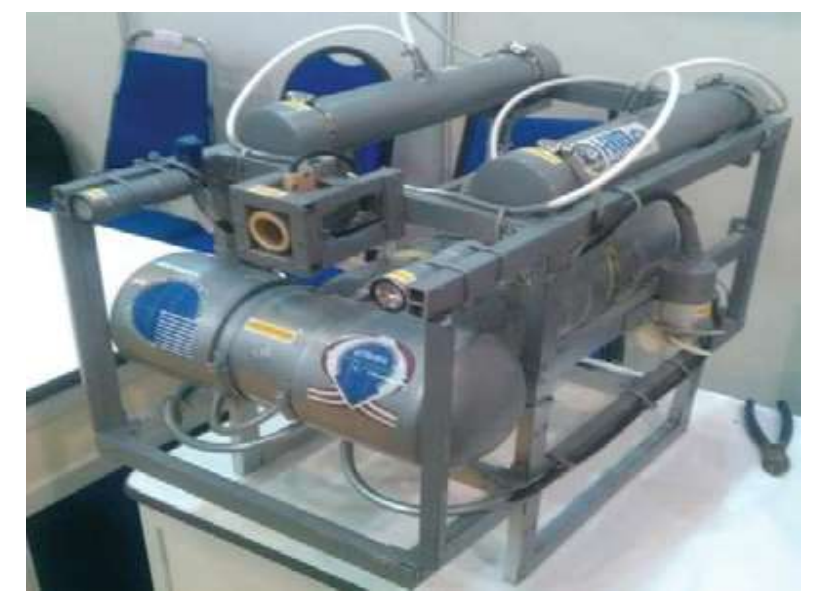

Figure 1. ROV developed by UTeRG.

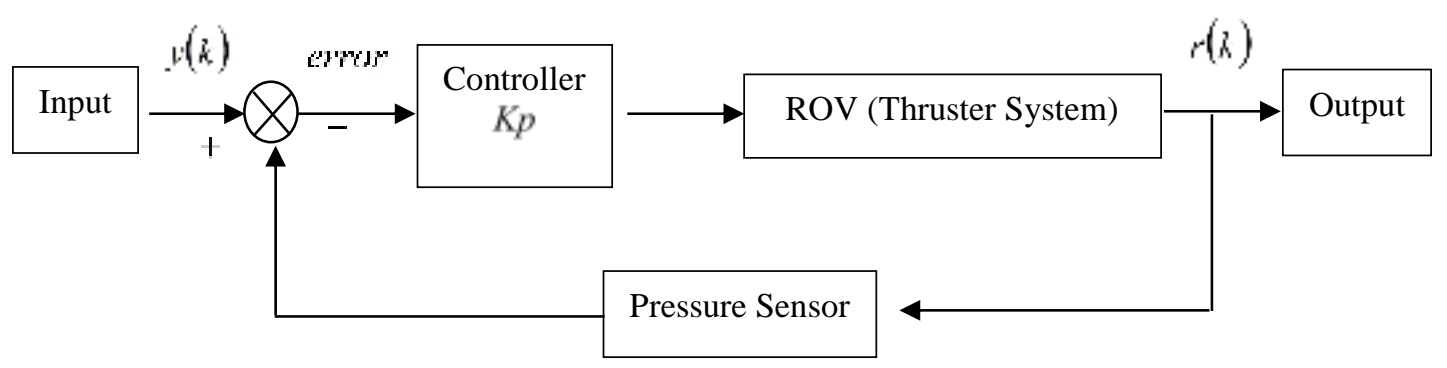

Figure 2. Control system overview.

\section{PROPOSED SYSTEM ARCHITECTURE}

The proposed auto depth control system depends on the pressure sensor for feedback signals, as shown in Figure 2. The pressure sensor will give feedback in the form of an analogue signal to the controller, either to stop or keep the thruster moving. The conventional proportional controller, $K p$, is used in this project. If the input signal is set to 1 meter, the pressure sensor will send feedback to the controller until it reaches 
1meter depth, while the controller will control the current flow through the thrusters by switching the current flow on and off to maintain the ROV. The prototype thruster with an auto depth control is controlled by a microcontroller; Figure 3 illustrates the control board and the thruster.

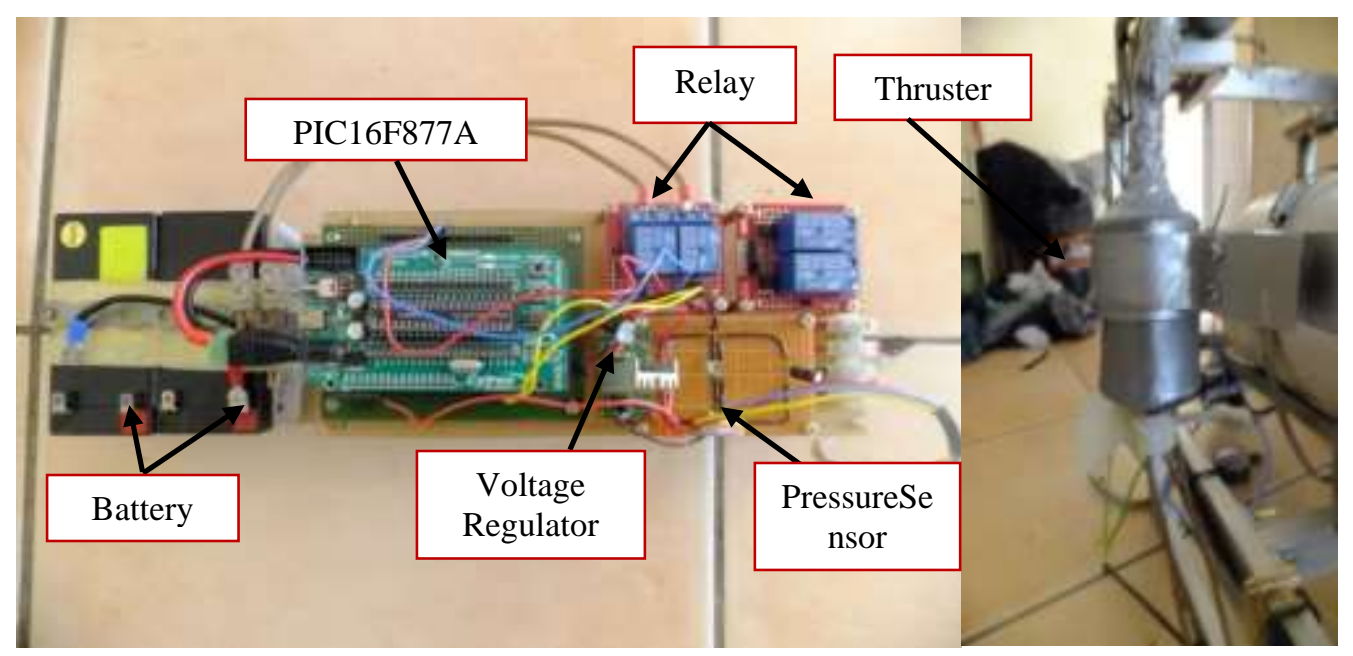

Figure 3. Control board and thruster.

\section{Thruster}

Recently, industrial ROV shave utilized a high power, high efficiency underwater thruster which is very expensive for educational uses. The proposed thruster for the ROV is an electric thruster. The thruster is a tip-driven electric thruster where the motor is structurally integrated into the propeller. This removes blockage of flow through the propeller, resulting in improved thrust production in a similar power requirement, as well as allowing for a shorter thruster length and bi-directional thrust. In addition, the thruster is designed using a low cost, low power $12 \mathrm{~V} \mathrm{DC}$ brushless motor and $45^{\circ}$ pitch angle with an $8 \mathrm{~cm}$ diameter propeller $[10,11]$. The ROV has two thrusters which are located on the right and left of the ROV to ensure that the thrusters can submerge smoothly and stably $[12,13]$.

\section{Pressure Sensor}

The pressure sensor measures the pressure, typically of gases or liquids, and usually acts as a transducer which generates a signal as a function of the pressure imposed. There are several types of analogue pressure sensor: piezoresistive strain gauge, capacitive, electromagnetic, piezoelectric, optical and potentiometric. For underwater use, the piezoresistive strain gauge and capacitive pressure sensor are both widely used for the auto depth control system due to their design for measuring the differential pressure. However, based on the advantages and disadvantages considered, this paper utilizes a piezoresistive strain gauge. Even though it has a high initial offset compared to the capacitive pressure sensor, it has high sensitivity and good linearity at constant temperature [14]. There are two types of piezoresistive strain gauge pressure sensor: MPX4250GP and MPX5700GP. Comparisons in terms of sensitivity between the sensors are made and Figure 4(a) shows the circuit diagram of the pressure sensors, and Figure 4(b) the actual pressure sensor. 


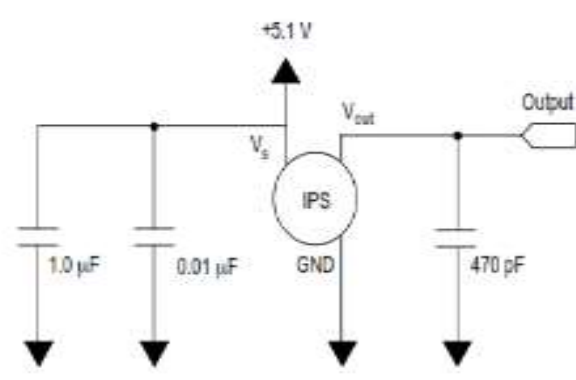

(a)

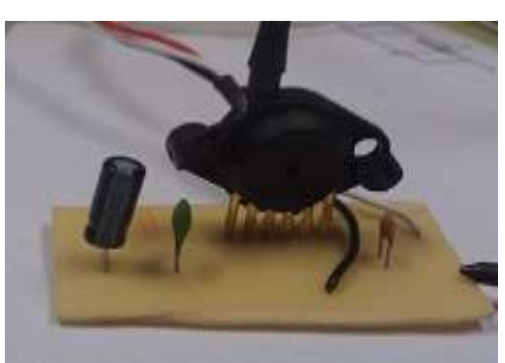

(b)

Figure 4. (a) Circuit diagram of pressure sensors, (b) Actual pressure sensor.

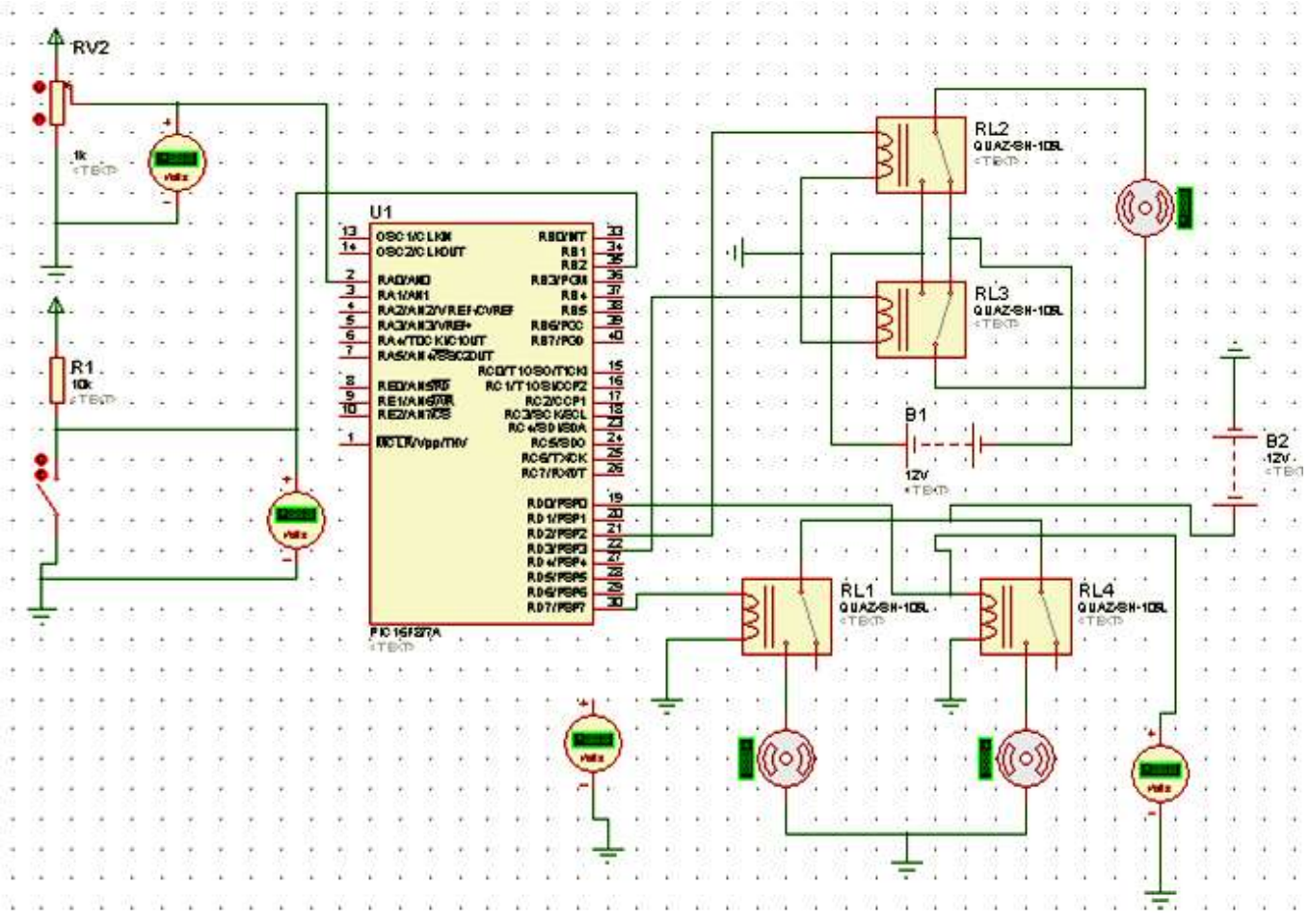

Figure 5. Auto-depth control with the PIC microcontroller using the Proteus software.

\section{PIC16F877A}

PIC16F877A is a small piece of semiconductor integrated circuit in a dual inline package (DIP) type. This package is easy to solder onto the strip board. However, it is easier to use a DIP socket so that the chip can be plugged and removed from the development board, helping to prevent the IC from any damage while it is being installed or removed. The benefit of it is the cheap price of one unit and the easy assembly. The IC can be reprogrammed and erased up to 10,000 times so that it is good for a new product development phase. The software used in the simulation process is Proteus, as shown in Figure 5, and to program the PIC MicroC is used, which acts as compiler to compile the programming and develops the hex file. The hex file is created after successfully compiling the program and needs to be loaded into the PIC16F877A using software called PIC kit. 


\section{SYSTEM PERFORMANCE ANALYSIS}

The performance of the pressure sensors is identified by testing the sensitivity pressure effect. In this test, output voltages from the pressure sensors as shown in Figure 4 are observed and then verified by using data from the sensor datasheet. The pressure sensors are connected with a pneumatic air regulator. The initial offset values of the MPX4250GP and MPX5700GP are $0.24 \mathrm{~V}$ and $0.18 \mathrm{~V}$ respectively. The testing is conducted by setting the air pressure at 0 bar as the initial value and slowly increasing the value by 0.5 bar at a time until 2.5 bar is reached. The output voltage of the pressure sensors is read using a multimeter. The results of both pressure sensors are plotted on a graph of the pressure versus output voltage.

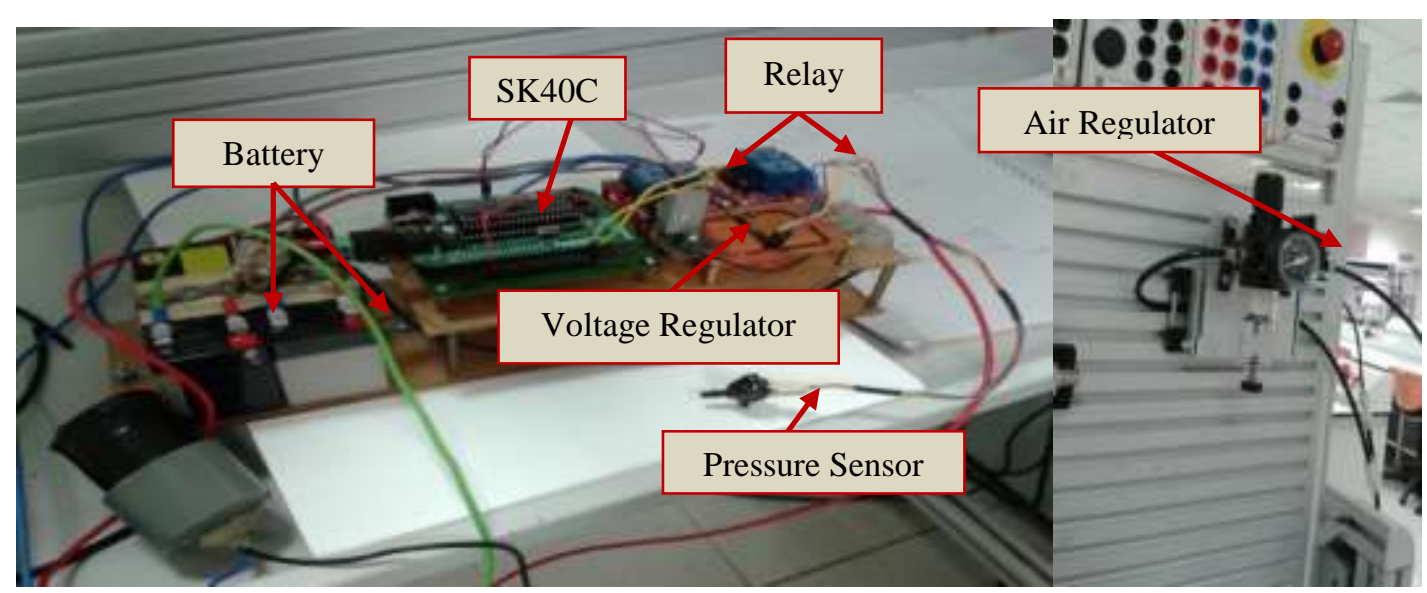

(a) Sensor and accuracy testing.

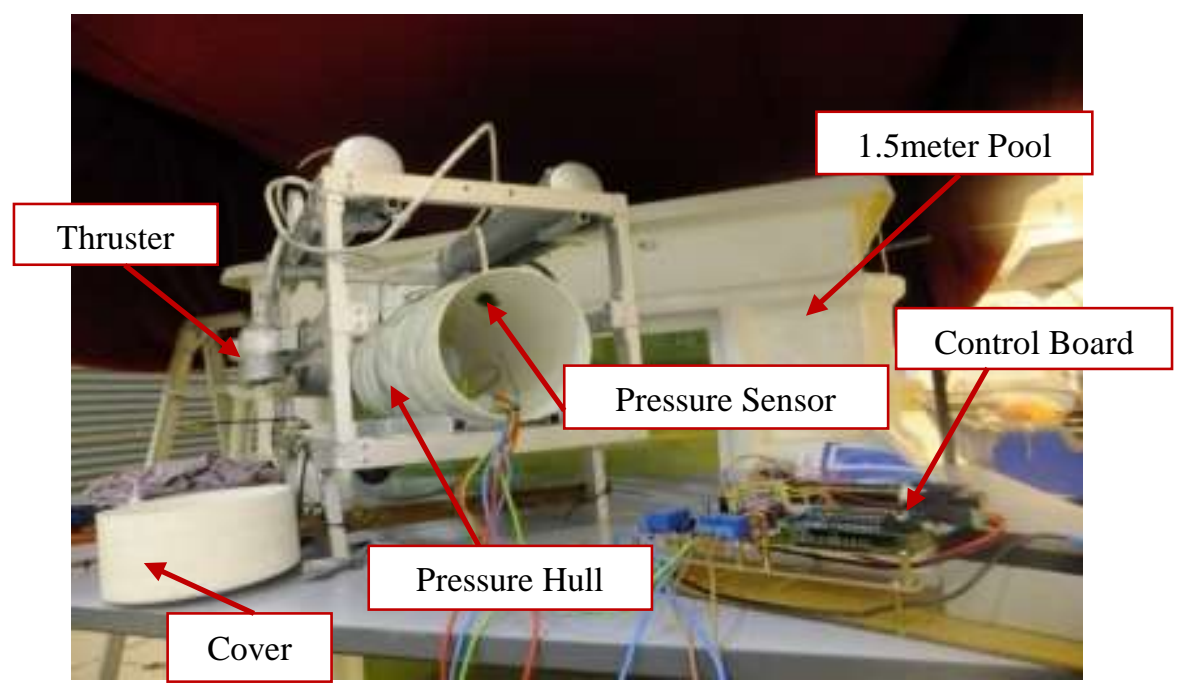

(b) Depth control and stability testing.

Figure 6. Experimental set-up.

The performance of the thrusters is identified by conducting accuracy and stability tests. Figure 6 (a) and (b) shows the experimental set-up for the testing. Before the accuracy and the stability test are conducted, the maximum depth that the ROV can achieve is observed and recorded. In the accuracy test, the saturation level is set and the time taken for the ROV to submerge until a saturation level is recorded. The results are 
plotted on a graph of time versus depth. For the stability test, to ensure that the ROV can remain at the set saturation level, although disturbances occur, the ROV is pushed from the back, left, right, front and 1 meter depth from the water surface. Movements in response to each disturbance are made and the ROV is observed. The results are recorded in Table 1.

Table 1. Effect of increasing $K p$.

\begin{tabular}{lllll}
\hline Parameters & Overshoot & Rise Time & Settling Time & Steady State Error \\
\hline$K p$ & Decrease & Increase & Small change & Decrease \\
\hline
\end{tabular}

\section{RESULTS AND DISCUSSION}

Figure 7 shows the ROV being tested in a Lab tank test. The performance of the pressure sensitivity of the MPX4250GP and MPX5700GP pressure sensors is demonstrated by plotting the pressure versus output voltage, as shown in Figure 8 . The result shows the similarity of the graph shape, but slightly differing values compared to the datasheet analysis result. Besides, MPX4250GP is more sensitive than MPX5700GP at the maximum 2.5 bar. Thus, the MPX4250GP pressure sensor can be utilized by the ROV for the auto depth control system [14]. Based on Aras et al. [14], the MPX 4250 GP pressure sensor has a lower percentage of error compared with other sensors that are used at depth, and this is another reason that this sensor is suitable for the range of depth for this project.

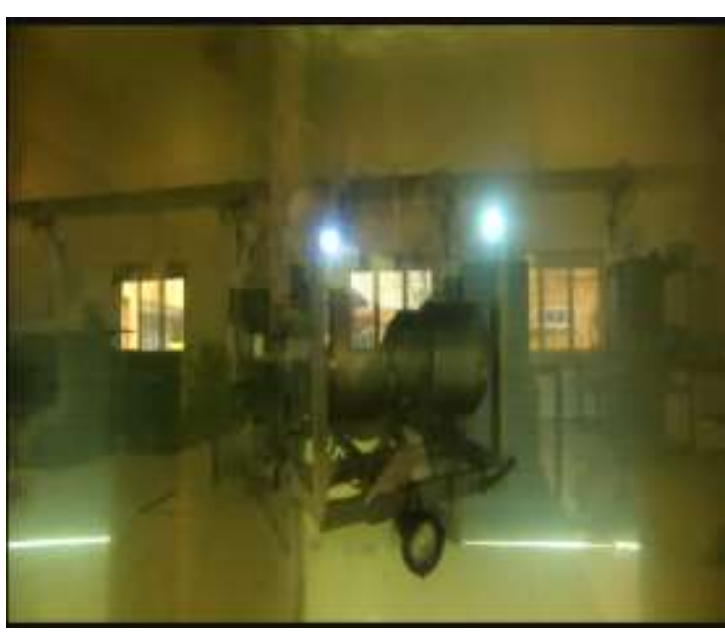

(a)

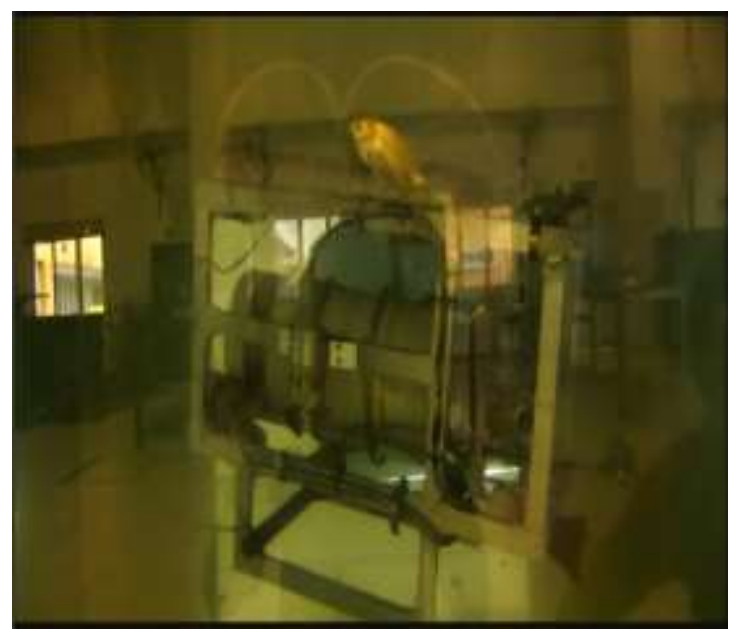

(b)

Figure 7. ROV tested for depth control.

From the observation, the maximum depth that the ROV can achieve is $0.7 \mathrm{~m}$ from the water surface. Figure 9 shows the average depth control test, where testing of depth control is done five times. For the depth control test, $0.5 \mathrm{~m}$ depth is set as the set point. The conventional proportional controller, $K p$, used is set to 1 , and the input signal is $0.33 \mathrm{~V}$ at $0.5 \mathrm{~m}$ depth. A larger $K p$ typically means a faster response since the larger the error, the larger the proportional term compensation. An excessively large proportional gain will lead to process instability and oscillation $[8,15]$. Table 1 shows the effect of the increasing value of every gain $K p$. It can be written as: 
where

$$
\text { error }=[y(k)-r(k)] * K p
$$

$y(k)$ is the input signal ; $r(k)$ is the pressure sensor output

$K p$ is the conventional proportional controller and is equal to 1

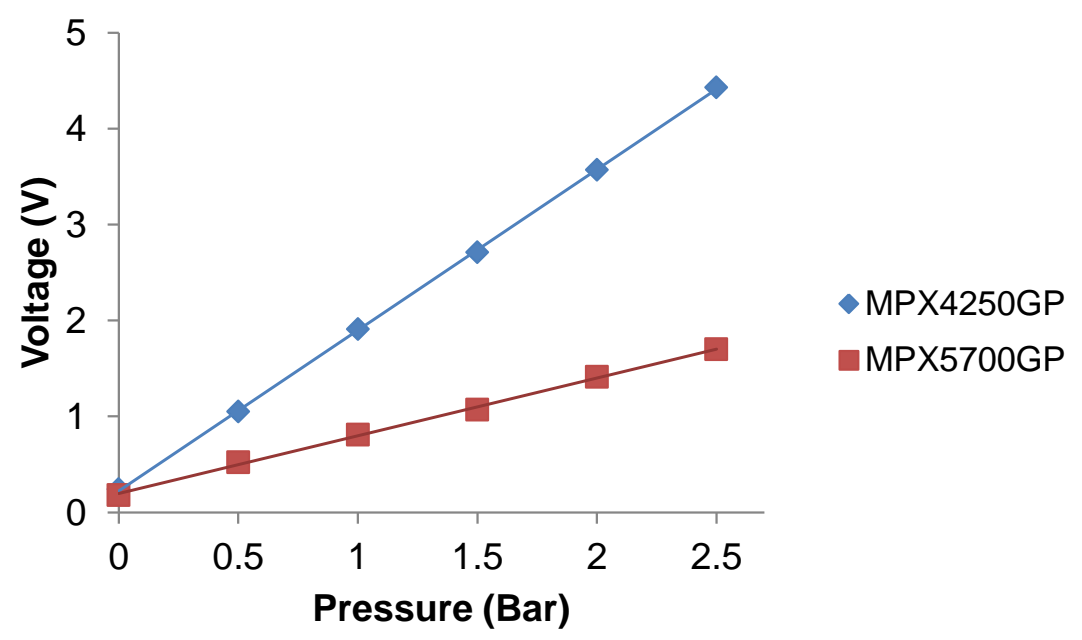

Figure 8. Output voltage of the piezoresistive strain gauge pressure sensor based on pressure.

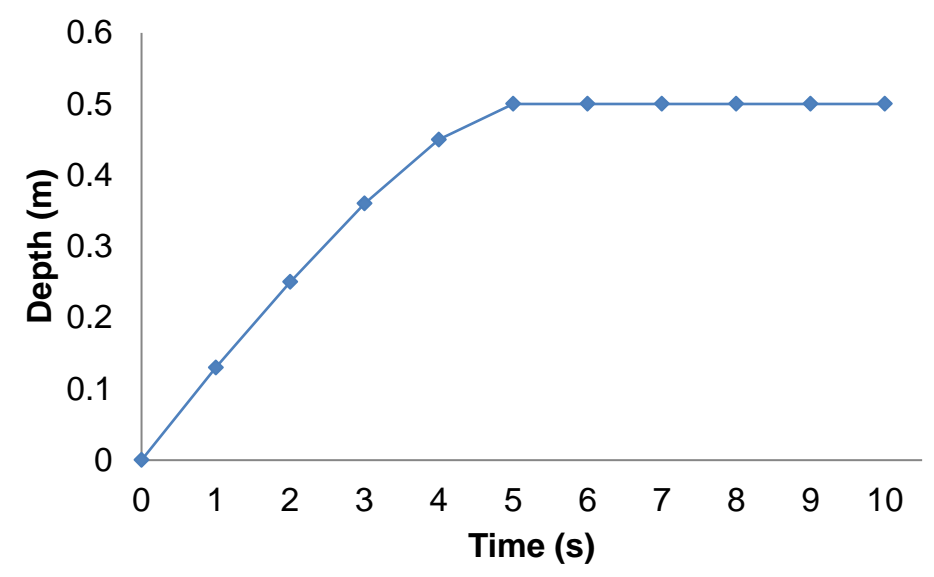

Figure 9. Time versus depth.

The results of the depth control and stability tests are shown in Figure 9 and Table 2 respectively. When the output signal is equal to the input signal, the error will be equal to 0 and the system will maintainthe ROV at the specified depth, as explained in Figure 2. As seen in Figure 9, no overshoot occurred for depth $0.5 \mathrm{~m}$ and the settling time for this response is $7 \mathrm{~s}$. For the stability test, although disturbances occurred, the ROV consistently returned and remained at $0.5 \mathrm{~m}$ depth, as shown in Figure 10 . The disturbance was created to test the controller and the thruster system to control the depth and shows that when there are dummy disturbances (after 10 seconds) the ROV will try to remain at the set point at 15 seconds onwards. Even when the disturbancesoccurred, the ROV looked stable, one reason for which is the open frame design. 
Table 2. Stability of the ROV.

\begin{tabular}{cccc}
\hline \multirow{2}{*}{ Disturbances } & \multicolumn{3}{c}{ Stability (no. of experiments) } \\
\cline { 2 - 4 } & 1 & 2 & 3 \\
\hline Back & YES & YES & YES \\
Left & YES & YES & YES \\
Right & YES & YES & YES \\
Front & YES & YES & YES \\
1m depth from water & YES & YES & YES \\
surface & & &
\end{tabular}

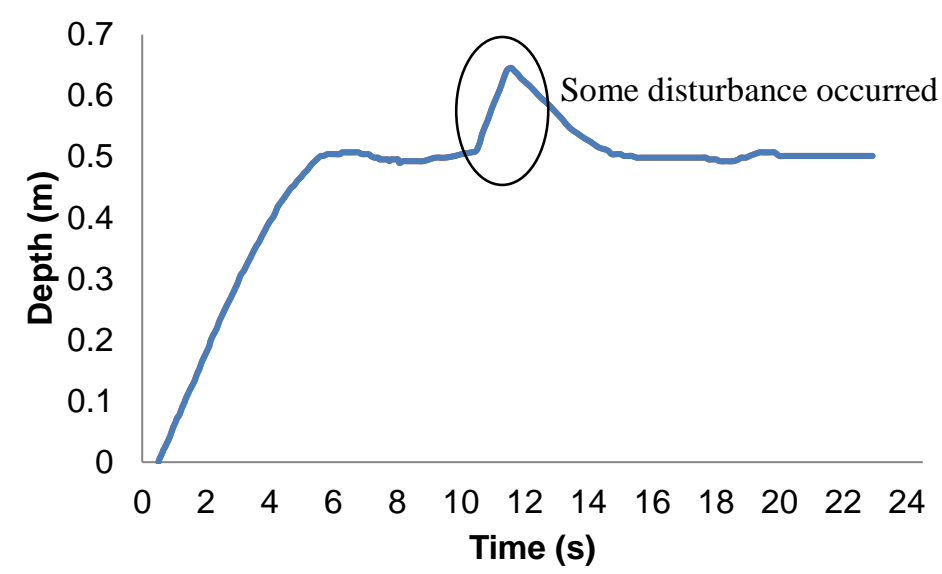

Figure 10. System response for depth control with disturbance.

\section{CONCLUSIONS}

This paper presents the design and development of a prototype ofan auto depth control using a thruster system. The thrusters are able to submerge the ROV until the maximum depth, as well as performing two main tasks which are maintaining the ROV at the specified depth for a long time and retaining the ROV at the initial depth when disturbances occur. The analysis results show that the auto depth control system usedperforms well and is suitable to be utilized by the UTeM ROV. For future work, an intelligent controller such as a Fuzzy Logic Controller can be applied in this project to compare the controller performances, and also a comparison witha simulation should be considered in further research.

\section{ACKNOWLEDGEMENTS}

The authors would like to thank Universiti Teknikal Malaysia Melaka (UTeM) for financial support and for providing the resources for this research.

\section{REFERENCES}

[1] Pohajdak T, Leahey J, Crossman M, Ferguson R. First Build Report Group 2: Aquatic cave exploration remotely operated vehicle (ACE ROV). Halifax, Canada: Dalhausie University. 2010; 1-40.

[2] Norsok. Remotely operated vehicle (ROV) services. Norwegian Technology Centre; 2003. 
[3] Aras MSM, Abdullah SS, Rashid MZA, Rahman AA, Aziz MAA. Development and modeling of unmanned underwater remotely operated vehicle using system identification for depth control. Journal of Theoretical and Applied Information Technology. 2013;56:136-45.

[4] Ali FA, Azis FA, Aras MSM, Othman MN, Abdullah SS. Design of a magnetic contactless thruster of unmanned underwater vehicle.International. Review of Mechanical Engineering. 2013;7:1413-20.

[5] Given D. ROV review 1993-1994. 5th ed. Spring Valley, CA: Windate Enterprises; 1993.

[6] Aras M, Shahrieel M, Ab Azis F, Othman MN. A Low Cost 4 DOF Remotely operated underwater vehicle integrated with IMU and pressure sensor. 4th International Conference on Underwater System Technology: Theory and Applications, Malaysia. 2012. p. 18-23.

[7] Azis F, Aras M, Rashid M, Othman M, Abdullah S. Problem identification for underwater remotely operated vehicle (ROV): A case study. Procedia Engineering. 2012;41:554-60.

[8] Aras MSM, Abdullah SS, Rahman AA, Aziz MAA. Thruster modelling for underwater vehicle using system identification method. International Journal of Advanced Robotic Systems: Underwater Vehicles. 2013;10:1-12.

[9] Aras MSM, Kassim AM, Khamis A, Abdullah SS, Aziz MAA. Tuning factor the single input fuzzy logic controller to improve the performances of depth control for underwater remotely operated vehicle. Modelling Symposium (EMS), 2013 European2013. p. 3-7.

[10] Chin C. Systematic modeling and model-based simulation of a remotely operated vehicle using MATLAB and Simulink. International Journal of Modeling, Simulation, and Scientific Computing. 2011;2:481-511.

[11] Lewis EV. Principles of Naval Architecture: Society of Naval Architects and Marine Engineers; 1988.

[12] Koh T, Lau M, Low E, Seet G, Swei S, Cheng P. Development and improvement of an underactuated underwater robotic vehicle. OCEANS'02 MTS/IEEE: IEEE; 2002. p. 2039-44.

[13] Koh TH, Lau MW, Low E, Seet G, Swei S, Cheng PL. A study of the control of an underactuated underwater robotic vehicle. International Conference on Intelligent Robots and Systems. 2002; 2049-54.

[14] Aras MSM, bin Abdullah SS, binti Shafei SS, Rashid MZA, Jamali A. Investigation and evaluation of low cost depth sensor system using pressure sensor for unmanned underwater vehicle. Majlesi Journal of Electrical Engineering. 2012;6:1-12.

[15] Salim M, Noordin A, Jahari A. A robust of fuzzy logic and proportional derivative control system for monitoring underwater vehicles. Second International Conference on Computer Research and Development. 2010; 84953. 